УДК 532.783

DOI 10.18101/2306-2363-2019-1-38-43

\title{
ИССЛЕДОВАНИЕ ЭЛЕКТРООПТИЧЕСКИХ СВОЙСТВ ПОЛИМЕРНО- ДИСПЕРСНЫХ ЖИДКИХ КРИСТАЛЛОВ, ДОПИРОВАННЫХ НАНОЧАСТИЦАМИ ОКСИДА ЖЕЛЕЗА
}

\section{(C) М. А. Цыренова}

аспирант,

Бурятский государственный университет 670000, Улан-Удэ, Смолина, 24а

E-mail: mtcyrenova93@mail.ru

\section{(C) Т. А. Чимытов}

старший преподаватель, Бурятский государственный университет 670000, Улан-Удэ, Смолина, 24а

E-mail: chimytov@gmail.com

\section{(C) Н. А. Романов}

научный сотрудник,

Институт физического материаловедения СО РАН 670047, Сахьяновой 6, Улан-Удэ

E-mail; nromanovv@mail.ru

\section{(C) С. В. Калашников}

директор ЦКП,

Бурятский государственный университет

670000, Улан-Удэ, Смолина, 24а

E-mail: betch_kail@mail.ru

\section{(C) Э. Ч. Хартаева}

младший научный сотрудник, Институт физического материаловедения СО РАН 670047, Сахьяновой 6, Улан-Удэ, Россия E-mail: erzhena.har@mail.ru

\section{(C) А. В. Номоев}

доктор физико-математических наук, директор, Институт физического материаловедения СО РАН 670047, Сахьяновой 6, Улан-Удэ, Россия E-mail: nomoevav@mail.ru

Представлены результаты экспериментального исследования влияния магнитных наночастиц оксида железа $\left(\mathrm{Fe}_{3} \mathrm{O}_{4}\right)$ на оптовременные характеристики нематических жидких кристаллов. Результаты исследования показывают, что введение наночастиц $\mathrm{Fe}_{3} \mathrm{O}_{4}$ в нематическую среду сокращает оптическое время отклика в электрическом поле. При этом уменьшается максимальное значение напряжения фотосигнала, что свидетельствует о снижении прозрачности образцов. Для чистых жидких кристаллов осциллограммы со временем не меняются 
M. А. Цыренова и др. Исследование электрооптических свойств полимерно-дисперсных жидких кристаллов допированных наночастицами оксида железа

Ключевые слова: нематические жидкие кристаллы; жидкокристаллические пленки; магнитные наночастицы; жидкие кристаллы; магнитные наночастицы; янус подобные наночастицы.

\section{Для цитирования:}

Цыренова М. А., Чимытов Т. А., Романов Н. А., Калашников С. В., Хартаева Э. Ч., Номоев А. В. Исследование электрооптических свойств полимерно-дисперсных жидких кристаллов допированных наночастицами оксида железа // Вестник Бурятского государственного университета. Химия. Физика. 2019. Вып. 1. С. 38-43.

В данной работе рассматриваются полимерно-дисперсные жидкие кристаллы (ПДЖК), включающие в себя микро- и наноразмерные наночастицы оксида железа $\mathrm{Fe}_{3} \mathrm{O}_{4}$. В последние годы добавление различных наночастиц в ПДЖК активно исследуется для улучшения их свойств $[1,2]$. Для работы были выбраны нематические жидкие кристаллы, так как нематики являются достаточно доступным для исследования материалом и легко управляемым. Они выдерживают существенные внешние механические и световые нагрузки. Допирование наночастицами ПДЖК пленок приводит к уменьшению размера капель жидких кристалл (ЖК) в процессе полимеризации, что влечет за собой снижение значений времен отклика и порогового напряжения.

Ранее нами определено, что янус подобные наночастицы обладают значительным дипольным моментом и уменьшают время включения ПДЖК $[3,4]$. Дипольный момент способствует дополнительному увеличению диэлектрической анизотропии ПДЖК по сравнению с оксидными и металлическими наночастицами, это дает уменьшение времен отклика ПДЖК. Прикладываемое электрическое поле разворачивает эти частицы в соответствии с их дипольным моментом, тем самым ускоряя поворот молекул нематических жидких кристаллов. В случае использования наночастиц, обладающих магнитным моментом, предполагается, что магнитные наночастицы будут взаимодействовать с электромагнитным полем, создающимся в результате изменения управляющего напряжения, подаваемого на ПДЖК. Очевидно, это приведет к изменению электрооптических свойств жидких кристаллов. Исследований, по влиянию магнитных наночастиц на электрофизические свойства ПДЖК, до настоящей работы не проводилось.

\section{Экспериментальное оборудование}

В качестве материалов для создания полимерно-дисперсных жидких кристаллов использовались следующие соединения: коммерческие поливинилацетат и нематический жидкий кристалл с положительной диэлектрической анизотропией 4-пентил-4'-цианобифенил (5СВ). Выбор этих компонентов объясняется их доступностью и достаточной изученностью. Для допирования исходной полимерно-жидкокристаллической смеси использовались наночастицы $\mathrm{Fe}_{3} \mathrm{O}_{4}$, которые были получены методом лазерной абляции в потоке кислорода [5]. Концентрация добавляемых частиц составила $1 \%$. Взвешивание суспензии производилась на аналитических весах (Vibra AF 224RCE). Смесь полимера, жидких кристаллов и наночастиц обрабатывалась ультразвуком в течение 10 мин при частоте 22 кГц. Полученный раствор наносился на стеклянную подложку с токопроводящим по- 
крытием. При испарении растворителя происходит фазовое разделение «жидкий кристалл - полимер». В результате образуется пленка, содержащая капли жидких кристаллов. После полного испарения растворителя пленку накрывают вторым стеклом с токопроводящим покрытием и помещают на 10 минут в печь, нагретую до $120^{\circ} \mathrm{C}$, затем охлаждают до комнатной температуры. Получившуюся ячейку помещают на экспериментальную установку для исследования жидкокристаллических систем [6]. На данной установке можно регулировать электрическое напряжение, необходимое для открытия ячейки жидких кристаллов, это позволяет исследовать зависимость их электрооптических свойств от управляющего напряжения. Установка эффективна при измерении быстродействия и световой прозрачности ячейки жидких кристаллов, так как частотой и напряжением электрического сигнала, подаваемого на ячейку, возможно управлять в широких пределах. Исследование оптического отклика образцов проводилось при подаче на них напряжения 62 В, являющимся напряжением насыщения (соответствующее 0,9 от величины максимального пропускания) и частотой сигнала 50 Гц.

Временные характеристики ЖК делятся на 2 периода: $\tau_{\text {оn }}$ - время включения ЖК и $\tau_{\text {off }}$ - время выключения ЖК. Сумма этих времен и дает в конечном счете время отклика жидких кристаллов [7]. Время включения и выключения описываются формулами:

$$
\begin{gathered}
\tau_{\text {on }}=\frac{4 \pi \eta}{\Delta s(f)} \frac{d^{2}}{\left(U^{2}-U_{0}^{2}\right)}, \\
\tau_{\text {off }}=\eta d^{2} / \pi^{2} K,
\end{gathered}
$$

где $\eta$ - вязкость ЖК, $\Delta \varepsilon(f)$ - диэлектрическая анизотропия, зависящая от частоты, $d$ - толщина слоя ЖК, $U$ - приложенное напряжение, $U_{0}$ - пороговое напряжение электрооптического эффекта, $K$ - коэффициент упругости Франка.

Пороговое напряжение $U_{0}$ зависит от свойств жидкого кристалла - диэлектрической анизотропии $\Delta \varepsilon$ и коэффициента упругости Франка [8].

Из формул видно, что ускорить процесс релаксации можно с помощью уменьшения вязкости жидкого кристалла, поднимая температуру ЖК и повышая коэффициент их упругости. Изменение напряжения, прикладываемого к слою жидкого кристалла, влияет только на ускорение оптического отклика нематического жидкого кристалла [9].

\section{Результаты и их обсуждение}

На рис. 1 показаны зависимости времен отклика чистых ЖК и ЖК, допированных наночастицами $\mathrm{Fe}_{3} \mathrm{O}_{4}$ в течении всего эксперимента. Видно, что время отклика ЖК, допированных наночастицами $\mathrm{Fe}_{3} \mathrm{O}_{4}$, изменяется со временем и в среднем уменьшается (линия 1). В то время как время отклика для чистых кристаллов не меняется (линия 2). С определенного момента (20 мин от начала эксперимента) время отклика ЖК $+\mathrm{Fe}_{3} \mathrm{O}_{4}$ становится меньше, чем в немодифицированных жидких кристаллах. Время отклика чистых ЖК не изменялось в течении 80 мин. Такое поведение времени отклика для ЖК, допированных наночастицами $\mathrm{Fe}_{3} \mathrm{O}_{4}$, может свидетельствовать об изменении (уменьшении) вязкости в течении всего эксперимента. 
M. А. Цыренова и др. Исследование электрооптических свойств полимерно-дисперсных жидких кристаллов допированных наночастицами оксида железа

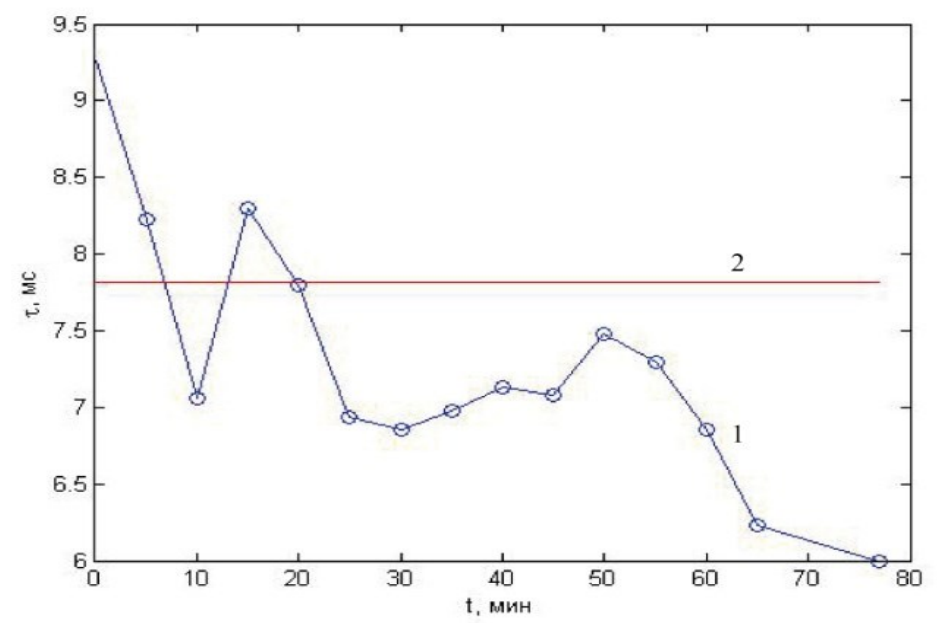

Рис. 1. Зависимости времен отклика чистых ЖК (линия 2) и ЖК допированных наночастицами $\mathrm{Fe}_{3} \mathrm{O}_{4}$ (линия 1) в течении всего эксперимента.

Результаты измерений электрооптических характеристик ПДЖК пленок, содержащих наночастицы $\mathrm{Fe}_{3} \mathrm{O}_{4}$, представлены на рис. 2. Показаны осциллограммы оптического отклика образцов с наночастицами $\mathrm{Fe}_{3} \mathrm{O}_{4}$ при подаче на них управляющего напряжения 62 В (рис. 2, слева). Значения времен отклика при этом изменяется от 8,23 мс до 6,23 мс. Видно, что с течением времени эксперимента время выключения уменьшается. При этом также уменьшается максимальное значение напряжения фотосигнала, что свидетельствует о снижении прозрачности образцов. Для чистых ЖК осциллограммы со временем не меняются (рис. 2, справа). Время отклика при этом равно 7,82 мс.
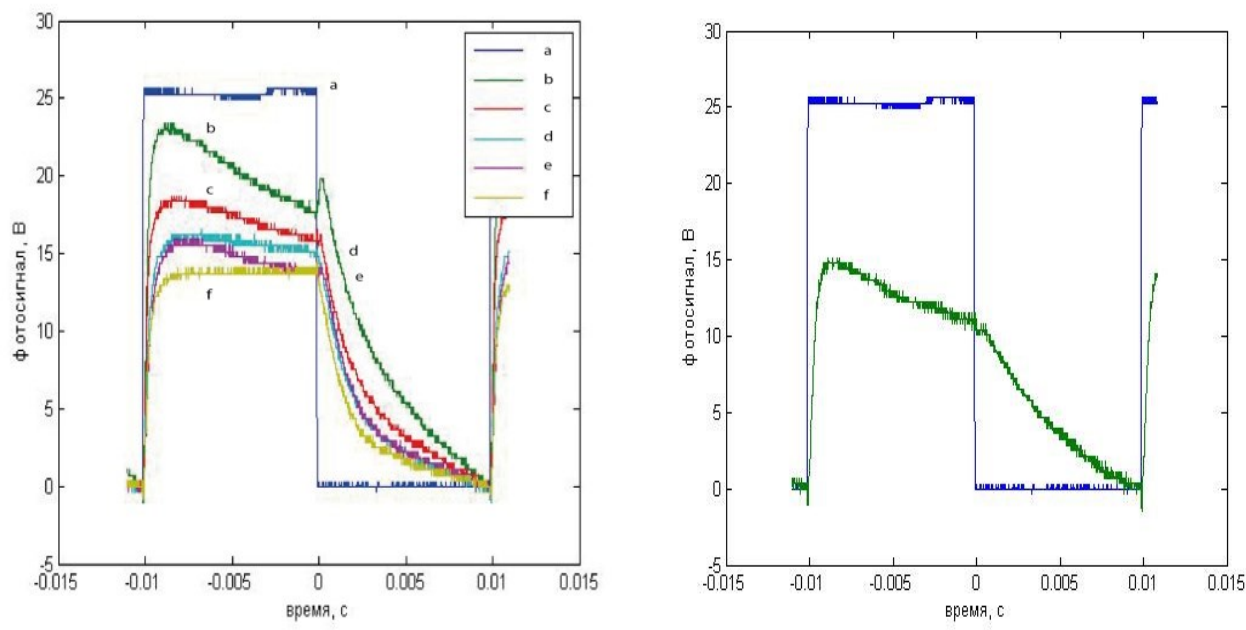

Рис. 2. Осциллограммы оптического отклика: слева - ПдЖК+ $\mathrm{Fe}_{3} \mathrm{O}_{4}$ a - управляющее напряжение; b - 15 с начала эксперимента; с -30 минут с начала эксперимента; d -45 минут с начала эксперимента; е - 60 минут с начала эксперимента; справа - чистые ПДЖк 


\section{Заключение}

Проведены исследования влияния магнитных наночастиц $\mathrm{Fe}_{3} \mathrm{O}_{4}$ на скорость оптического отклика полимерно-дисперсных жидкокристаллических пленок.

При добавлении наночастиц $\mathrm{Fe}_{3} \mathrm{O}_{4}$ времена отклика в среднем уменьшаются. С определенного момента времени время отклика ПДЖК, допированных наночастицами $\mathrm{Fe}_{3} \mathrm{O}_{4}$, становится меньше чем в чистом ПДЖК. Полученные данные показывают целесообразность использования наночастиц $\mathrm{Fe}_{3} \mathrm{O}_{4}$ для модификации ПДЖК-композиции.

Исследование выполнено за счет гранта Российского научного фонда (проект № 18-79-10143).

\section{Литература}

1. Подъячева О. Ю., Матус Е. В., Субоч А. Н., Жаркова Г. М. Оптические свойства полимерно-дисперсных жидкокристаллических композитов, допированных углеродными нанотрубками // Жидкие кристаллы и их практичическое использование. - 2018. - Т. 18, № 3. - С. 53-58

2. Подъячева О. Ю., Матус Е. В., Субоч А. Н., Жаркова Г. М. Исследование закономерностей формирования полимерно-дисперсных жидкокристаллических материалов, допированных углеродными нанотрубками // Жидкие кристаллы и их практическое использование. - 2018. - Т. 18, № 3. - С. 82-88.

3. Andrey V. Nomoev, Sergey P. Bardakhanov, Makoto Schreiber, Dashima Zh. Bazarova, Boris B. Baldanov and Nikolai A. Romanov. Characterization, and Mechanism of Formation of Janus-Like nanoparticles of Tantalum Silicide-Silicon $\left(\mathrm{TaSi}_{2} / \mathrm{Si}\right) / /$ Nanomaterials. — 2015. — № 5 . - P. 26-35

4. Номоев А. В., Бардаханов С. П. Синтез и механизм образования янусподобных наночастиц силицида тантала-кремния $\left(\mathrm{TaSi}_{2} / \mathrm{Si}\right) / /$ Плазменная эмиссионная электроника: труды IV междунар. Крейнделевского семинара. — 2012. - С. 190-193.

5. Хартаева Э. Ч., Номоев А. В., Бардаханов С. П., Шолохов Е.С., Батороев А. С., Сызранцев В. В., Жалсанов Б. Г., Лыгденов В. Ц. Получение, характеризация и применения магнитных наночастиц созданных лазерной абляцией // Вестник Бурятского государственного университета. Химия. Физика. - 2018. - Вып. 2-3. С. 3-14.

6. Романов Н. А., Номоев А. В., Калашников С. В. Установка для измерения электрооптических свойств жидких кристаллов // Вестник Бурятского государственного университета. Химия. Физика. — 2015. - № 3. - С.114-117.

7. Чигринов В. Г. Ориентационные эффекты в нематических жидких кристаллах в электрическом и магнитном полях // Кристаллография. - 1982.- Т. 27, Вып. 2. - С. 404-430.

8. Lopatina L. M., Selinger J. V. Theory of Ferroelectric Nanoparticles in Nematic Liquid Crystals // Phys. Rev. Lett. - 2009. - V. 102. — 197802.

9. Блинов Л. М. Электрооптические эффекты в жидких кристаллах // УФН. - 1974. - Т. 114, Вып. 1. - С. 67-96. 
M. А. Цыренова и др. Исследование электрооптических свойств полимерно-дисперсных жидких кристаллов допированных наночастицами оксида железа

STUDY OF ELECTROOPTIC PROPERTIES OF POLYMER-DISPERSE LIQUID CRYSTALS DOPED BY IRON OXIDE NANOPARTICLES

\author{
M. A. Tsyrenova \\ Postgraduate \\ Buryat State University, Ulan-Ude \\ 670000, Ulan-Ude, Smolina Str., 24a \\ E-mail: mtcyrenova93@mail.ru
}

T. A. Chimytov

старший преподаватель

Buryat State University, Ulan-Ude

670000, Ulan-Ude, Smolina Str., 24a

E-mail: chimytov@gmail.com

\title{
N. A. Romanov
}

Researcher

Institute of Physical Materials Science SB RAS

Sakhyanova Str. 6, Ulan-Ude, 670042, Russia

E-mail; : nromanovv@mail.ru

S. V. Kalashnikov

директор ЦКП,

Buryat State University, Ulan-Ude

670000, Ulan-Ude, Smolina Str., 24a

E-mail: betch_kail@mail.ru

E. Ch. Hartaeva

Researcher

Institute of Physical Materials Science SB RAS

Sakhyanova Str. 6, Ulan-Ude, 670042, Russia

E-mail: erzhena.har@mail.ru;

\section{A. V. Nomoev}

доктор физико-математических наук, директор

Institute of Physical Materials Science SB RAS

Sakhyanova Str. 6, Ulan-Ude, 670042, Russia

E-mail: nomoevav@mail.ru

The paper presents the results of an experimental study of the effect iron oxide nanoparticles $\left(\mathrm{Fe}_{3} \mathrm{O}_{4}\right)$ on the wholesale characteristics of nematic liquid crystals. The results of the study show that the introduction of $\mathrm{Fe}_{3} \mathrm{O}_{4}$ nanoparticles into a nematic medium reduces the response time in an electric field. This reduces the maximum value of the voltage of the photo signal, which indicates a decrease in the transparency of the samples. For pure liquid crystals, the waveforms do not change over time.

Keywords: nematic liquid crystals; liquid crystal films; magnetic nanoparticles; liquid crystals; magnetic nanoparticles; Janus-like nanoparticles. 